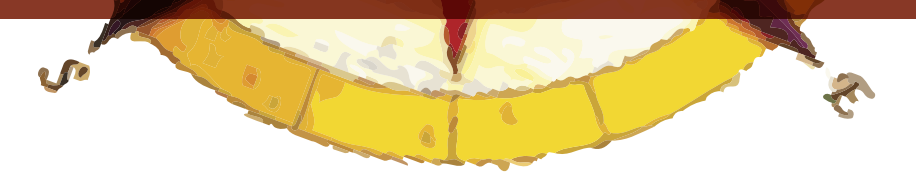

\title{
CONSTRUÇÃO DO PENSAMENTO ESPACIAL CRÍTICO: O PAPEL DA LEITURA E DA ESCRITA NO ENSINO DA GEOGRAFIA
}

\author{
Vanilton Camilo de Souza ${ }^{19}$
}

\section{RESUMEN}

El artículo indica los elementos considerados fundamentales para el proceso de construcción del conocimiento geográfico en la escuela. Con este fin, se hace uso en la primera parte de la construcción de conceptos en Vygotski como una dimensión teórica capaz de orientar los procesos de aprendizaje en la enseñanza de la geografía, lo que resultaría en la construcción de un pensamiento espacial por parte del estudiante. La segunda parte se refiere al papel de la lectura y la escrita como actividades escolares potenciales al proceso de construcción de los conceptos de la geografía.

Palabras clave: enseñanza de la geografia, construcción de conceptos, pensamiento espacial.

\section{RESUMO}

O presente texto aponta elementos considerados fundantes do processo de construção do conhecimento geográfico no âmbito escolar. Para tanto, recorre-se, na primeira parte do texto, à construção de conceitos na perspectiva vygotskiana como dimensão teórica capaz de orientar os processos de aprendizagem no ensino de Geografia, que resultaria na construção de um pensamento espacial por parte do aluno. Na segunda parte, recorre-se ao papel da leitura e da escrita como atividades escolares potencializadoras do processo de construção de conceitos geográficos.

Palavras-chave: ensino de geografia, construção de conceitos, pensamento espacial.

\begin{abstract}
This text points out considered foundational elements of the construction of geographical knowledge in the school. For this purpose, we have recoursed in the first part of the text, to the construction of concepts in the Vygotskian perspective as theoretical dimension capable of guiding the learning processes in the teaching of geography, which result in the construction of a spatial thinking by the student. The second part refers to the role of reading and writing as a potentiating school activities of the construction of geographical concepts.
\end{abstract}

Professor do Instituto de Estudos Socioambientais da Universidade Federal de Goiás. 
Keywords: teaching geography, building concepts, spatial thinking.

\section{INTRODUÇÃO}

Neste texto, discutem-se os pressupostos de que: um ensino eficaz é aquele que cumpre com a função escolar na formação de um cidadão autônomo e crítico capaz de superar os problemas que afligem a sociedade atual; o cumprimento da função escolar se assenta essencialmente nos processos de aprendizagem em que o aluno é capaz de construir seus conceitos; a Geografia ensinada nas escolas desenvolve nos alunos um pensamento espacial próprio da disciplina; o ensino da Geografia decorre de metodologia capaz de cumprir o papel da Geografia e da escola.

Toma-se ainda como referência ao que se pretende neste texto alguns apontamentos de Cavalcanti sobre o papel da Geografia e, pressupostamente, o papel da escola:

Cabe reafirmar e explicitar a importância da Geografia escolar para a formação geral de cidadãos. Na relação cognitiva de crianças, jovens e adultos com o mundo, o raciocínio espacial é necessário, pois as práticas sociais cotidianas têm uma dimensão espacial. Os alunos que estudam essa disciplina já possuem conhecimentos nessa área oriundos de sua relação direta e cotidiana com o espaço vivido. Sendo assim, o trabalho de educação geográfica é o de ajudar os alunos a analisarem esses conhecimentos, a desenvolverem modos do pensamento geográfico, a internizarem métodos e procedimentos, de captar a realidade vivida e "apresentada" pela geografia escolar, tendo consciência de sua espacialidade. Esse modo de pensar geográfico é importante para a realização de práticas sociais variadas, já que essas práticas são sempre práticas socioespaciais. (2006, p. 34)

Nesse sentido, é fundamental referenciar-se pelos conceitos estruturantes do pensamento espacial, bem como os conceitos que potencializam a formação do pensamento. Souza (2011) aponta que a construção do pensamento espacial decorre de processos epistêmicos próprios da didática da Geografia, que, por sua vez, se fundamentam com base nas teorias e metodologias próprias da Geografia, da Filosofia, da Psicologia e da Educação. Isso significa que a noção de Geografia como ciência que compreende a produção do espaço, a noção de mediação da psicologia histórico-cultural de Vygotski e a noção de retificação do erro da filosofia bachelardiana são, para o autor, os fundamentos para um pensamento espacial crítico.

Nessa primeira parte do texto, será trabalhada a noção vygotskiana de construção de conceitos, entendendo-a como dimensão intrinsecamente articulada à noção de mediação do autor, para com isso, ampliar o papel da Didática da Geografia como campo que se ocupa da formação de um pensamento espacial e dos processos de aprendizagem da Geografia. Com o objetivo de potencializar esse campo, tendo por base a noção de construção de conceito, será trabalhado, ainda, o papel da leitura e da escrita na segunda parte do texto.

Antes, porém, vale ressaltar as intensas contribuições de L. Vygotski, pensador situado no campo da Psicologia e da Educação. As influências de Vygotski nas ideias educacionais brasileiras não são antigas, manifestando-se timidamente no final dos anos de 1970. Na década de 1980, foi quando ocorreu a adoção mais intensa desse teórico nas pesquisas educacionais.

Nas pesquisas sobre o ensino da Geografia, Vygotski é referenciado essencialmente a partir dos anos de 1990. Apesar da forte influência na educação de maneira geral, um levantamento realizado pelo Núcleo de Estudos e Pesquisa em Educação Geográfica (NEPEG) evidenciou que foram pou- 
cas as pesquisas sobre o ensino dessa disciplina referenciadas por esse teórico (Zanatta; Santos; Souza, 2008). Apesar de poucas investigações realizadas, foram evidentes as contribuições de Vygotski para o processo de aprendizagem de conteúdos geográficos.

Vygotski $(1998 ; 2000)$ diz que os meios social e cultural ocupam espaços significativos para entender a participação do indivíduo nesse meio e seu processo de aprendizagem. Para isso, ele cria a noção de estruturação das funções psíquicas superiores. Esse princípio se colocava na contramão do pensamento da época que consistia em analisar como o meio social age no indivíduo, criando nele funções superiores de origem essencialmente social. A exemplo dessa afirmação, Vygotski (2001) se contrapõe a Piaget, por conceber que o desenvolvimento segue não no sentido da socialização, mas no da conversão das relações sociais em funções mentais.

O problema das funções psíquicas superiores constitui o núcleo central do sistema de Vygotski e este se baseia no pensamento histórico-dialético. Para compreender o sistema de ideias apresentado por Vygotski, é fundamental explicitar seu entendimento sobre o desenvolvimento das funções psíquicas superiores. Estas devem ser entendidas como a atividade simbólica composta por suas formas exteriores (linguagem, leitura, escrita etc) e interiores (atenção, memória, pensamento).

As funções psíquicas superiores constituem uma nova formação psíquica que aparece depois de outros processos psíquicos elementares e nunca se apresenta de forma acabada. É o resultado da influência cultural na aprendizagem e no desenvolvimento e só podem ser explicadas em sua gênese por sua história, situando-a em seu contexto de origem.

$\mathrm{Na}$ base das funções psíquicas superiores, situa a atividade laboral e com ela a atividade mediadora do homem, que inclui o uso de instrumentos e de signos em sua ação sobre a realidade e sobre si mesmo. Para Vygotski (2000), instrumentos e signos funcionam como estímulos aos processos mentais. São meios artificiais introduzidos pelo homem em situações psicológicas, como exemplo, tem-se a linguagem. Dessa forma, assimila-se as formas e ações sociais de atuação e as transfere para si próprio. Todas essas formas de conduta, signos e instrumentos são produtos do desenvolvimento da cultura humana criada pelo próprio homem, dentro dos quais, Vygotski (2000) considerou como núcleo central a linguagem e seus significados verbais, como mecanismo determinante em todas as formas de atividade do homem.

Apesar de não ser exclusiva, a linguagem é o mais privilegiado dos sistemas mediadores na transmissão racional, cultural, intencional e do pensamento. A linguagem, como instrumento simbólico que regula as relações com os demais, está integrada funcionalmente à ação, ao converter-se em um instrumento do pensamento dedicado à busca de tarefas cognitivas e práticas. Para Vygotski, esse processo de formação das estruturas psíquicas superiores funciona como se fosse uma lei psicológica que atua em dois planos: primeiro como algo social, depois como algo psicológico; primeiro como categoria interpsíquica no grupo, depois como categoria intrapsíquica no indivíduo (Vygotski, 1998; 2000).

A essência desse processo reside no fato de se considerar o externo como social. Assim, qualquer função psíquica superior foi externa porque foi social antes de ser interna. Antes de ser uma função psíquica propriamente dita, foi uma relação social entre pessoas.

Vale ressaltar que diversos processos mentais potencializam as funções psíquicas superiores e, em 
decorrência disso, a construção do conhecimento acontece. Nos processos mentais, a construção de conceitos é fundante.

\section{CONHECIMENTO ESPACIAL: DOS CONCEITOS ESPONTÂNEOS AOS CONCEITOS CIENTÍFICOS}

Qual é o sentido dos conceitos em nossa prática social? Para que servem os conceitos geográficos na vida cotidiana? É através dos conceitos que se enxerga uma dada realidade. Uma mesma realidade pode se apresentar de diferentes formas dependendo dos tipos de conceitos - com os cotidianos enxergamos a realidade de uma forma, com os científicos, de outra forma. Com os conceitos cotidianos de paisagem, por exemplo, o aluno pode identificar os objetos no espaço, sua forma. O conceito de paisagem de base dialética, por exemplo, possibilita o aluno ir além da paisagem e das formas dos objetos no espaço. Ir além da paisagem implica saber quem construiu os objetos no espaço, para quem esses objetos foram construídos, como os objetos espaciais foram usados ao longo do tempo, por quem, que contradições expressam. É possível, com o conceito científico sobre essa base, ver que a paisagem tem uma história, tem processos sociais, econômicos, políticos, culturais, éticos.

No ensino da Geografia, a passagem dos conceitos espontâneos (cotidianos) aos conceitos científicos não é tarefa fácil. Para que ocorra a construção de conceitos, considera-se importante quatro princípios teóricos práticos.

O primeiro princípio refere-se ao fato de que os conceitos não se constroem pela transmissão de conteúdos. Os alunos necessitam de mecanismos que possibilitem a internalização e a significação dos conteúdos como condição capaz de modificar os conceitos espontâneos.

É recorrente na formação inicial do professor de Geografia, nos seus trabalhos escolares, explicitar que uma das condições básicas para ensinar Geografia é partir da realidade do aluno. Assim, pode-se elaborar atividades de ensino, tendo por base os elementos que compõem o conceito geográfico. Aos poucos, é possível fazer com que esses conceitos internalizem e possibilitem o surgimento de outros significados dos conceitos espontâneos. É recorrente, por outro lado, em suas primeiras experiências em sala de aula, aquilo que foi escrito nas atividades não ser levado em conta. É comum nessas experiências não tomar conhecimento sobre a realidade do aluno para preparar as aulas nem tampouco se preocupar se os conteúdos geográficos possuem relação com os conceitos espontâneos e se serão significativos para os alunos. E mais. Os modelos das aulas se repetem em relação aos modelos como transmissão de conteúdos. Nos primeiros momentos das aulas, expõe-se oralmente, de forma resumida, o conteúdo. Essa exposição é seguida de leitura de um texto didático sobre o assunto para, com isso, responder aos exercícios solicitados pelo professor. Opondo-se à ideia de transmissão, aponta-se que a construção de conceito decorre de atividades complexas, como se apresenta a seguir neste texto.

No segundo princípio, toma-se o fato de que a construção de conceitos decorre de processos mentais complexos. Vygotski (2004) discute a dimensão da complexidade que envolve o pensamento e aponta para a relação existente entre o pensamento e a ação motora do indivíduo e a influência psicológica do pensamento na ação, com intuito de mostrar que o pensamento é resultado de obstáculos que se coloca para as pessoas. Dessa forma, pensar é um ato importante para a aprendizagem. Para o autor, ensinar sem a existência de barreiras ao pensamento significa antes de tudo extirpar toda a dificuldade para a aprendizagem. 
[...] ao criar o caminho mais fácil e cômodo para assimilar conhecimento, ao mesmo tempo paralisa na raiz o hábito do pensamento independente, tira da criança essa preocupação e afasta conscientemente da educação todos os momentos de elaboração complexa da experiência, exigindo que todo o necessário seja levado ao aluno em forma desmembrada, mastigada e digerida. Entretanto, é necessário que nos preocupemos precisamente com a criação do maior número possível de dificuldades na educação da criança como pontos de partida para os seus pensamentos (Vygotski, 2004, p. 237- 238).

Straforini (2004, p. 88) aponta a existência do denominado "modelo sintético" que, ao ensinar Geografia, deve-se valorizar o estudo das espacialidades próximas do aluno, sob o argumento de que o processo de aprendizagem seria "mais fácil" ao passo que as localidades mais distantes seriam "mais difíceis" de promover uma aprendizagem mais significativa. Nesse sentido, instaurou-se no ensino da Geografia uma metodologia em que, nos primeiros anos de escolaridade, ensina-se sobre a casa e a escola, depois se amplia para o bairro, para a cidade, para o município, para o estado, para o país e assim sucessivamente. É uma metodologia de ensino de Geografia baseada na ideia de "círculo concêntrico", em que o "eu" (fácil) é o ponto de referência para o processo de aprendizagem e vai se deslocando para espaços mais "distantes" (difícil) à medida que a criança vai ampliando seu processo de aprendizagem e/ou escolaridade.

O complexo, no caso, não decorre do crescimento da escala e sim das relações que se pode estabelecer entre as diversas escalas espaciais. Segundo Straforini (2004), não devemos conceber essa linearidade nas escalas, tendo em vista a complexidade do mundo globalizado. Para o autor, o espaço geográfico, independentemente das escalas, deve ser analisado como totalidade-mundo.

Alderoqui (2006) problematiza essa questão de se considerar o próximo como uma espacialidade fácil e simples. A autora afirma que a dificuldade ou a facilidade para os alunos aprenderem não está na proximidade ou na distância do fenômeno e sim na complexidade do objeto e na maneira pela qual os professores recortam os aspectos que vão ensinar sobre um determinado espaço. Dessa forma, a casa, a escola, a rua, o bairro contêm elementos que se articulam com outros espaços e são fundamentais na compreensão do lugar.

O terceiro princípio situa-se no fato de que os conceitos espontâneos, decorrentes das experiências espaciais, e os conceitos científicos, decorrentes da Geografia, não são polos opostos. O espontâneo é ponto de partida para a construção do conhecimento, via conceitos científicos.

Quando se aponta que os alunos no seu cotidiano possuem saberes e práticas sociais que reverberam em práticas espaciais, diz-se, então, que os alunos possuem um saber geográfico (conceitos espontâneos) construído a partir das experiências da família, da escola, da rua, dos meios de comunicação. Como já mencionado anteriormente, os conceitos espontâneos orientam tais práticas que raramente resultam de sua personalidade. À escola e aos conteúdos de Geografia cabem a tarefa de desenvolver novos conceitos com base nos existentes. Qual é o ponto de partida para ensinar Geografia nessa perspectiva? Como construir conceitos científicos com base nos conceitos espontâneos?

Em relação à primeira pergunta, pode-se dizer que o ponto de partida para o planejamento das aulas de Geografia e para a seleção dos conteúdos é conhecer a geografia praticada pelos alunos. Para tanto, procedimentos diversos devem ser utilizados recorrentemente. Pequenos questionários aplicados aos alunos, o uso de desenhos, o recorte de figuras, as visitas ao entorno da escola, os diálogos em sala de aula, dentre outros, constituem-se importantes instrumentos para acessar as geografias praticadas cotidianamente pelos alunos. A partir dos dados, podem-se planejar algumas 
aulas e selecionar os conteúdos que proporcionem a construção dos conceitos geográficos por parte do aluno.

Quando se diz que conceitos geográficos e conceitos espontâneos não são opostos, tomam-se as referências de Bachelard (2004) sobre o papel do erro na construção do conhecimento. O erro tem sido bastante estudado no campo educacional, pois essa noção implica uma perspectiva didática no processo de construção do conhecimento. Tais estudos tendem a apontar a dimensão negativa à didática que usa o erro para punir e classificar; discriminar os que aprendem dos que não aprendem; diferenciar os que merecem boas notas daqueles que não deram conta de passar de ano. Por outro lado, há uma positividade do erro no processo de ensino, tendo em vista as reais possibilidades de o aluno construir seus próprios conceitos e, com isso, ser sujeito autônomo em sua aprendizagem. $\mathrm{Na}$ prática pedagógica, o erro pode significar uma possibilidade concreta de evoluir o pensamento.

Sem dúvida, ao classificar as singularidades da substância, o cientista retoma os métodos do estudo de extensão, mas o problema da identificação terá mudado de caráter ao mudar de nível. Procede-se por eliminação das diferenças e não por aproximação das qualidades comuns. Um não é igual ao outro, pois os métodos de eliminação enfatizam um tempo da dialética de identificação quase sempre desprezado pelos estudiosos da lógica. Não se trata de uma eliminação pura e simples; para estimar o valor do que se conserva, leva-se em conta o que é eliminado. Por isso, o problema do erro parece mais importante do que o problema da verdade. Isso revela que só encontramos uma solução possível para o problema da verdade quando afastamos erros cada vez mais refinados (Bachelard, 2004, p. 246).

O autor está se referindo, portanto, à positividade do erro, encarado como elemento motor do conhecimento e uma etapa a ser atravessada. Essa compreensão implica considerar as concepções alternativas como condições necessárias ao desenvolvimento cognitivo individual. Assim, é bastante natural para a epistemologia bachelardiana a existência de concepções alternativas, reveladoras das "impurezas e valores" adquiridos pelo conhecimento sensível, na interação dos sujeitos com outros sujeitos e do sujeito com o mundo que o cerca.

A objetividade de uma ideia será mais clara e mais distinta, na medida em que ela aparecer sobre um fundo de erros mais profundos e mais diversos. É preciso errar para atingir um fim. Não há verdades primeiras, só erros primeiros. A primeira e mais rica função do sujeito é a de se enganar. Quanto mais complexo for seu erro, mais rica será sua experiência. A experiência é a lembrança dos erros retificados. "O erro é uma fase da dialética que precisa ser transposta. Ele suscita uma investigação mais precisa, é o motor do conhecimento" (Bachelard, 2004, p. 251).

Assim, conhecer a geografia do cotidiano do aluno, evidenciando os erros que o sustenta é, ao mesmo tempo, uma possibilidade de se vislumbrar o papel dos conceitos geográficos capazes de retificá-los.

Por fim, o quarto princípio decorre do fato de que o conceito será construído pelo aluno se o conhecimento científico tiver vínculo com suas experiências e for mais significativo do que o conhecimento espontâneo. Isso significa que o aluno aprendeu, internalizou, construiu significado. Nessa perspectiva, a aprendizagem resulta dos processos educativos em que a experiência do aluno é inteiramente determinada pelo meio e, nesse processo, o papel do professor consiste em organizar e regular o meio (Vygotski, 2004). O autor critica a perspectiva tradicional do ensino em que o professor ensina os conteúdos e o aluno "aprende" sem a garantia de que houve a internalização. A 
garantia dessa internalização é decorrente da experiência do aluno e é isso que se caracteriza como elemento básico da aprendizagem. Enfatiza, nesse processo, o papel do professor como mediador e o papel da escola como espaço capaz de promover aprendizagens diferentes dos demais processos educativos. As aprendizagens advindas do processo educativo escolar é uma das preocupações centrais do autor.

Sendo a construção de conceitos aspecto fundante das estruturas psíquicas superiores e a escola como espaço central desse processo, pode-se dizer que algumas atividades escolares são essenciais. Destaca-se, na próxima seção deste artigo, o papel da leitura, o papel da escrita e o papel da metacognição como atividades potencializadoras da construção de conceitos com destaque à formação do pensamento espacial crítico.

\section{LEITURA E ESCRITA: ATIVIDADES ESCOLARES FUNDANTES DA CONSTRUÇÃO DO PENSAMENTO ESPACIAL}

Numa pesquisa em que se verificou como os alunos do curso de graduação em Geografia construíam conhecimento, Souza (2009) destacou, dentre outros aspectos, o papel da leitura e da produção de texto como atividades importantes nas aprendizagens durante a formação inicial. A leitura era a estratégia utilizada quando aparecia a dúvida, quando os alunos estavam motivados, quando tinham interesse de ir além do que viam na sala de aula.

Qual é a relação entre leitura e construção do pensamento? Para iniciar, veja-se o que a leitura representa no âmbito dos processos mentais, conforme apontam Fontana e Rossetti:

Pensar a leitura implica, inicialmente, reconhecer sua natureza como processo altamente complexo, que abrange várias dimensões e operações interligadas e interdependentes, seja do ponto de vista estritamente linguístico e cognitivo ou, mais amplamente, semiótico e social. (2007, p. 188)

O processo de leitura e de compreensão do texto, para ser satisfatório, exige a coordenação de várias habilidades relacionadas: a percepção da realidade, o uso da memória, as inferências que se realizam, os julgamentos do texto ou dos discursos, as práticas sociais e espaciais nas quais estão inseridas, dentre outras. Além disso, é preciso considerar que existem outros elementos que afetam o resultado da leitura, como o momento quando se realiza a leitura, o lugar onde ela ocorre e, até mesmo, a qualidade do material impresso. Dessa forma, o que se sabe é que ler é uma operação intelectual que ultrapassa o ato mecânico de identificar o escrito. Pode ser considerado um importante motor do pensamento e, portanto, do processo de construção de um pensamento crítico. Como esse processo se reverbera a um pensamento espacial? Qual é a importância da leitura para o ensino da Geografia?

Para elucidar melhor a associação da leitura com o processo de construção de um pensamento espacial, tome-se a perspectiva de Freire (1994), que considera que o ato de ler é muito mais profundo do que operar uma decodificação de palavras e de frases. Para Freire (1994), ler é participar das concepções expressas no texto lido; é mergulhar em representações expressas pelo autor. Significa, ainda, descortinar, mudar de horizontes, interagir com o real, interpretá-lo, compreendê-lo e decidir sobre ele. Assim, entende-se que um texto só pode ser lido se o reescrevemos. O mesmo ocorre com a leitura da realidade. Para Freire (1994), não lemos apenas as palavras, os textos e os livros; lemos o mundo, isto é, tudo aquilo que está ao nosso redor. O mundo em que vivemos é um texto, portanto, 
as diversas espacialidades desse mundo são textos. As paisagens, os locais de relações cotidianas das pessoas e as conexões como outras localidades diversas exigem uma leitura mais crítica dessas espacialidades.

Nessa perspectiva, a leitura da realidade precede a leitura da palavra. Aprendemos a ler o mundo antes mesmo de decodificar os sinais gráficos das letras. Assim, ler o mundo é tão importante quanto ler a palavra, pois um não está dissociado do outro. São dois momentos que se comunicam no ato de pensar, pois existe uma relação mútua entre a leitura do mundo e a leitura da palavra, entre a linguagem e a realidade, entre o texto e o contexto (Freire, 1994).

Infere-se, assim, que a leitura da realidade socioespacial só ocorre quando se reescreve, quando se transformam as diversas espacialidades em pensamento espacial. Isso significa dizer que, epistemologicamente, são bons leitores das espacialidades do mundo que transformam esse mundo real e textual em um mundo cognitivo. Desse modo, conforme Freire (1994), para o "ciclo gnosiológico" se realizar, é preciso ler e reelaborar o lido, estudar e refazer o estudado, aprender e reaplicar o aprendido, observar e intervir no incessante processo de transformação social, assumindo humanamente a vocação de sujeitos históricos, inacabados e, por isso mesmo, em constante transformação.

Para que a leitura se efetive nessa perspectiva, há de se considerar a adoção de uma metodologia que leve o aluno a ler, a compreender e a sintetizar o texto para, em seguida, dar significado, comparar e relacionar com outros textos ou com situações sobre a realidade.

No ensino da Geografia, quando se diz ler o texto, não nos referimos apenas ao escrito, apesar de o texto ser considerado a forma mais estruturada de organização das ideias. Há, no entanto, várias formas de explicitar os conteúdos geográficos. O mapa, a fotografia, as formas espaciais, dentre outros, cada um possui seus signos próprios para serem lidos para, com isso, operar seus significados. Se os signos são espaciais e explicitam conteúdos espaciais, os respectivos significantes se reverberam em dimensões capazes de desenvolver um pensamento espacial no aluno.

$\mathrm{O}$ ato de ler é uma atividade escolar e geográfica fundante ao que se pretende neste texto. $\mathrm{O}$ ato de escrever é, concomitantemente ao ato de ler, importante no processo de construção do conhecimento. Se a leitura é fértil à ação cognitiva, a produção das narrativas pelos escolares é fundante à metacognição, conceito e atividade que será tratada posteriormente aqui.

Segundo Cunha (1997), na produção das narrativas, a pessoa pode destacar situações, suprimir episódios, reforçar influências, negar etapas, lembrar e esquecer. Tudo isso tem muitos significados e as possíveis contradições podem ser exploradas com fins pedagógicos. Além dessa vinculação cognitiva ao aluno que as escreve, as narrativas significam componente metodológico potencializador de identificação de erros e, ao mesmo tempo, como potencial de retificação de tais erros. Permitem, portanto, uma mediação mais eficaz. Tê-las como instrumento de mediação no processo de aprendizagem pode ser visto no que se segue:

A narrativa provoca mudanças na forma como as pessoas compreendem a si próprias e aos outros. Tomando-se distância do momento de sua produção, é possível, ao "ouvir" a si mesmo ou ao "ler" seu escrito, que o produtor da narrativa seja capaz, inclusive, de ir teorizando a própria experiência. Este pode ser um processo profundamente emancipatório em que o sujeito aprende a produzir sua própria formação, autodeterminando a sua trajetória. É claro que esta possibilidade requer algumas condições. É preciso que o sujeito esteja disposto a analisar criticamente a si próprio, a separar olha- 
res enviezadamente afetivos presentes na caminhada, a por em dúvida crenças e preconceitos, enfim, a des-construir seu processo histórico para melhor poder compreendê-lo (Cunha, 1997, s/p).

Diversas podem ser as formas de orientar a produção das narrativas nas aulas de Geografia, atendo-se com clareza às metodologias próprias à produção de texto com destaque às que incitam os alunos a escreverem. Recentemente, com a intensa utilização da informática, pode-se utilizar desse recurso para as diversas formas de se escrever. A construção de blogs, a inserção em redes sociais, o geoprocessamento, dentre outras formas, potencializam a produção de narrativas geográficas pelos alunos.

\section{A METACOGNIÇÃO COMO PROCESSO EPISTÊMICO PRÓPRIO DA LEITURA E DA ESCRITA}

A metacognição refere-se ao controle que o aluno possui sobre seu processo de aprendizagem e de construção do conhecimento. Os estudos sobre a metacognição nesse processo são recentes na literatura educacional. Segundo Ribeiro (2003), esses estudos surgiram nos anos de 1970 e evidenciaram a importância das estratégias próprias dos alunos na construção do conhecimento, bem como quando utilizá-las nesse processo. Tais estudos evidenciaram também que a utilização de estratégia e/ou as modificações das estratégias já usadas anteriormente e a verificação de diferenças significativas no desempenho escolar decorrentes das estratégias cognitivas e metacognitivas produzem alunos mais aptos na organização de seu conhecimento e na regulação de seu processo cognitivo. Os estudos revelaram ainda que "a metacognição exerce influência em áreas essenciais da aprendizagem escolar, tais como, na comunicação e na compreensão oral e escrita e na resolução de problemas, constituindo, assim, um elemento-chave no processo de aprender a aprender" (Ribeiro 2003, p. 110).

A leitura, como processo metacognitivo, necessita de estratégias para tal, conforme o que segue:

A variável estratégia inclui informações sobre os meios, processos ou ações que permitem ao sujeito atingir os objetivos com maior eficácia numa determinada tarefa. Neste sentido, possuir um repertório razoável de estratégia não é o suficiente, é também necessário ter um conhecimento aprofundado sobre eles (Ribeiro, 2003, p. 110-111).

As narrativas, por sua vez, como atividades resultantes da metacognição, podem ser referenciadas por Benjamim (1994), ao apontar que o narrador inspira-se em sua experiência para contar o que ele conta. A narrativa é, portanto, fruto de sua própria experiência relatada por ele ou pelos outros. O narrador pode incorporar as coisas narradas à experiência dos seus ouvintes, "pode recorrer ao acervo de toda uma vida, uma vida que não inclui apenas a própria experiência, mas em grande parte a experiência alheia". (Benjamim, 1994, p. 321).

A metacognição pode ser marcante no ato da escrita das narrativas por parte dos alunos. Ela pode ser um dos fatores que mobiliza o ser humano na árdua tarefa da construção do conhecimento. $\mathrm{O}$ professor, no entanto, deve participar desse processo exercendo o papel de fornecer informações e de orientações que permitam aos seus alunos o desenvolvimento da consciência em torno do seu processo de aprendizagem. Um dos caminhos para a prática do processo de metacognição é criar problemas em vez de resolvê-los. Será a partir deles que se estimulará o pensamento e, ao mesmo tempo, se verificará o que está sendo construído. A capacidade metacognitiva será maior quando o professor planejar sua ação na sala de aula, tendo isso como atividade intencional. Na medida em 
que o professor possibilita ao aluno o desenvolvimento de sua capacidade cognoscitiva, a capacidade de organizar seu pensamento, esse professor estará efetivando sua ação mediadora no processo de construção do conhecimento.

\section{OUTRAS CONSIDERAÇÕES}

Destacou-se neste texto a importância da noção de construção de conceito na perspectiva da teoria histórico-cultural de Vygotski como dimensão fundante da estruturação do pensamento espacial. Para tanto, procurou-se abordar as dimensões teóricas e práticas no processo de transformação dos conceitos espontâneos em conceitos geográficos. Diversos outros conceitos vygotskianos foram utilizados, demonstrando o quanto a teoria é produtiva para a didática da Geografia. Ressalta-se, ainda, que vários outros conceitos de Vygotski têm relação com o que foi tratado, porém, não foram amplamente discutidos neste texto, com destaque para o papel da linguagem e da mediação na construção de conceitos e, no caso, para a construção do pensamento espacial. Nesse sentido, é imperativo o desenvolvimento dos referidos conceitos em tarefas posteriores.

Outra consideração diz respeito à vastidão das possibilidades de se vincular as teorias vygotskianas ao ensino da Geografia, bem como de relacioná-las a outros teóricos que possam potencializar nossa tarefa de pensar o papel da escola e da Geografia voltado para um aluno crítico, autônomo, com personalidade própria, capaz de realizar ações positivas para si e para a sociedade de forma justa e ética.

\section{BIBLIOGRAFIA}

Alderoqui, S. Enseñar a pensar la ciudad. In: Alderoqui, S.; Penchansky, P. (Compiladoras). (2006). Ciudad y ciudadanos. Aportes para la enseñanza del mundo urbano. Buenos Aires: Paidós.

Bachelard, G. (2004). Ensaio sobre conhecimento aproximado. Rio de Janeiro: Contraponto.

Benjamin, W. (1994). Obras escolhidas: Magia e Técnica, Arte e Política. São Paulo: Brasiliense.

Cavalcanti, L. S. (2006). Formação de professores, concepções e práticas no ensino da Geografia. Goiânia: Vieira.

. (2005). Cotidiano, Mediação pedagógica e formação de conceitos: uma contribuição de Vygotsky ao ensino de Geografia. Caderno Cedes. 25(66).

Cunha, M. I. (1997). Conta-me: as narrativas como alternativas pedagógicas na pesquisa e no ensino. Revista da Faculdade de Educação. 23 (1-2), São Paulo.

Fontana, N. M.; Rossetti, M. (2007). Relendo a relação entre conhecimento enciclopédico e leitura. Linguagem e Ensino. 10(1), p. 187-210.

Freire, P. (1994). A importância do ato de ler: em três artigos que se completam. São Paulo: Cortez.

Ribeiro, C. (2011). Metacognição: um apoio ao processo de aprendizagem. Psicologia: Reflexão e Crí- 
tica. 16(1), p. 109-116. Disponível em: <http://www.scielo.br/pdf/prc/v16n1/16802.pdf>. Acesso em: 22 de nov. 2011.

Souza, V. C. (2011). Fundamentos teóricos, epistemológicos e didáticos no ensino da Geografia: bases para formação do pensamento espacial crítico. Revista Brasileira de Educação em Geografia. $1(1)$, p. 47-67. . (2009). O processo de construção do conhecimento geográfico na formação do professor de Geografia. Tese (Doutorado em Geografia). IESA/UFG, Goiânia, GO.

Straforini, R. (2004). Ensinar Geografia, um desafio da totalidade-mundo nas séries iniciais. São Paulo: Annablume.

Vygotski, L. S. (1998). A formação social da mente. São Paulo: Martins Fontes, 1998. . (2004). Psicologia Pedagógica. São Paulo: Martins Fontes, 2004. . (2000). Obras Escogidas III. Madrid: Apredizaje Visor.

Zanatta, B. A.; Souza, V. C.; Santos, A. D. F. (2008). O ensino do conceito de lugar: do pensamento empírico ao pensamento teórico. Goiânia: UCG. (Relatório da pesquisa)

Artículo recibido 20 - 09 - 11. Aprobado $25-11-11$. 